\title{
Female Alcoholics. Electrocardiographic Changes and Associated Metabolic and Electrolytic Disorders
}

\author{
Paulo Borini, J osé Henrique Imaca Terrazas, Arlindo Ferreira Júnior, Romeu Cardoso Guimarães, \\ Sabrina Bicalho Borini \\ Marília, SP - Brazil
}

\begin{abstract}
Objective - To identify the electrocardiographic changes and their associations with metabolic and electrolytic changes in female alcoholics.

Methods - The study comprised 44 female alcoholics with no apparent physical disorder. They underwent the following examinations: conventional electrocardiography; serologic tests for syphilis, Chagas' disease, and hepatitis $B$ and $C$ viruses; urinary pregnancy testing; hematimetric analysis; biochemical measurements of albumin, fibrinogen, fasting and postprandial glycemias, lipids, hepatic enzymes, and markers for tissue necrosis and inflammation.
\end{abstract}

Results - Some type of electrocardiographic change was identified in 33(75\%) patients. In 17(38.6\%) patients, more than one of the following changes were present: prolonged QTc interval in 24 (54.5\%), change in ventricular repolarization in 11(25\%), left ventricular hypertrophy in 6 (13.6\%), sinus bradycardia in $4(9.1 \%)$, sinus tachycardia in $3(6.8 \%)$, and conduction disorder in $3(6.8 \%)$. The patients had elevated mean serum levels of creatine phosphokinase, aspartate aminotransferases, and gamma glutamyl transferase, as well as hypocalcemia and low levels of total cholesterol and LDL-cholesterol. The patients with altered electrocardiograms had a more elevated age, a lower alcohol consumption, hypopotassemia, and significantly elevated levels of triglycerides, postprandial glucose, sodium and gamma glutamyl transferase than those with normal electrocardiograms. The opposite occurred with fasting glycemia, magnesium, and alanine aminotransferase.

Conclusion - The electrocardiographic changes found were prolonged QTc interval, change in ventricular repolarization, and left ventricular hypertrophy. Patients with normal and abnormal electrocardiograms had different metabolic and electrolytic changes.

Keywords: alcoholism, females, electrocardiographic changes

\section{Hospital Espírita de Marília}

Mailing address: Paulo Borini - Rua Gabriel Monteiro da Silva, 40

Cep 17501-150 - Marília, SP, Brazil - E-mail: fborini@unimedmarilia.com.br

Received 11/25/02

Accepted 4/14/03

English version by Stela Maris C. e Gandour
In men and women, abusive ingestion of alcohol is associated with arterial hypertension ${ }^{1-3}$, cardiac arrhythmias ${ }^{4}$, and cardiac muscle impairment with several structural and functional abnormalities ${ }^{5-8}$.

Myocardial lesions are expected to occur when the daily alcohol consumption is greater than $80 \mathrm{~g}$ for an approximate period of 10 years ${ }^{9}$. However, lower daily doses (around 60g) for longer periods (approximately 25 years) may cause dilated cardiomyopathy, arrhythmias, and cardiac hypertensive disease ${ }^{5,10}$. A subgroup of chronic alcoholics with a greater sensitivity to development of hepatopathy, probably due to genetic reasons, exists. As such, vulnerability to cardiac changes may also depend on constitutional predisposition ${ }^{11}$.

The following mechanisms have been cited as participating in the physiopathogeny of heart disease due to alcohol: direct action of alcohol or its metabolites on the cardiac muscle causing inflammation and fibrosis ${ }^{12}$, macro- and microangiopathic changes ${ }^{13,14}$, electrolytic changes, participation of metabolic and nutritional factors ${ }^{15,16}$, and the toxic effect of the additives present in alcoholic beverages ${ }^{17}$. Deficiency in thiamin itself does not seem to be the cause of alcoholic cardiomyopathy ${ }^{18}$, because it is associated with low cardiac output and systemic vasoconstriction, while, in the cardiomyopathy of beriberi, an elevated cardiac output occurs with reduced peripheral vascular resistance ${ }^{4}$.

The increasing prevalence of female alcoholism among us ${ }^{19,20}$ will certainly be a serious public health problem in the near future because of the increase in morbidity and mortality resulting from abusive alcohol consumption. If the cardiovascular problems of male alcoholism have not been sufficiently studied in Brazil, even less has been done in regard to female alcoholism. Women have been reported to be more susceptible than men are to diseases related to chronic alcoholism, even when ingesting a lower amount of alcohol. The difference in susceptibility between the sexes has been related to different proportions of body water and fat $^{21}$ and different rates of alcohol metabolism ${ }^{22}$. Therefore, women would be more susceptible than men in regard to 
cardiomyopathy and myopathy ${ }^{5}$. Asymptomatic alcoholic females have a lower ejection fraction and greater ventricular mass than do nonalcoholic females ${ }^{5}$.

The medical problems caused by alcoholism are usually preceded by social and psychic problems for several years. Consequently, alcoholics admitted to specialized units for the treatment of addiction comprise a group different from those admitted to clinical hospitals for the treatment of physical problems. Most studies on the cardiac changes in chronic alcoholics assess the latter group of alcoholics, ie, patients with evident clinical manifestations. The information about the changes occurring when the symptoms are not evident or are very mild is scarce.

This study aimed at assessing the frequency and type of electrocardiographic changes in chronic alcoholic patients with no manifestation of previous heart disease and at detecting the metabolic and electrolytic changes associated with them.

\section{Methods}

According to the principles of the Helsinki Declaration and after informed written consent, female patients diagnosed with alcoholism (IDC-10 1997) ${ }^{23}$ and admitted to a psychiatric hospital (Hospital Espírita de Marília, HEM) from October 1993 to September 1994 were studied.

The patients came from the Center of First Assistance and Triage of the Hospital de Clínicas of the Medical School of Marília, where they underwent clinical and psychiatric examinations and were considered suitable for the psychiatric treatment at the HEM, because they had no relevant organic problems. Within the first 24 hours after hospital admission, the patients once again underwent a complete clinical examination and were considered clinically asymptomatic with no evidence of hepatic, renal, cerebral, or cardiac dysfunction. Information was gathered after the phase of alcoholic intoxication through an interview based on a medical form comprising, among other items, psychiatric and clinical anamnesis ${ }^{24}$. At the time of hospital admission, the patients were using alcohol exclusively, and none of them had used any medication or other licit or illicit drug in the 30 days preceding hospitalization.

Blood for laboratory tests was collected within the first 24 hours of admission after a 10- to 12-hour fast and no pharmacological therapy. The following laboratory tests were performed: qualitative serology for syphilis, Chagas' disease, and hepatitis B and C viruses; serum levels of hemoglobin, albumin, fibrinogen, lipids, fasting and postprandial glycemias, electrolytes, creatine phosphokinase, lactic dehydrogenase, and hepatic enzymes; and the urinary pregnancy test.

Conventional electrocardiograms at rest were recorded with the FUNBEC - ECG 4 device and were interpreted by 2 cardiologists. When they disagreed, a third cardiologist was consulted. The QT interval was measured from the beginning of the QRS complex to the end of the T wave. When the $\mathrm{U}$ wave was present, the QT interval was measured at the nadir of the curve between the $\mathrm{T}$ and $\mathrm{U}$ waves. The duration of the QT interval was calculated using the Bazett formula in the D2 lead and was considered altered for women when the value found for QTc was greater than $440 \mathrm{~ms}^{25,26}$.

Systemic blood pressure was measured on hospital admission and on subsequent days with a mercury sphygmomanometer on the left upper limb with the patient seated. The first and last Korotkoff sounds were used to determine systolic and diastolic blood pressure, respectively. Three measurements were taken at 1-minute intervals in the morning, afternoon, and evening periods for 5 consecutive days. The mean of the 3 measurements in each period was considered the blood pressure value in the period, and the mean of the values obtained in the 3 periods was considered the patient's blood pressure. Arterial hypertension was diagnosed according to the criteria of the Joint National Committee (JNC VI) ${ }^{27}$ when systolic blood pressure was $\geq 140 \mathrm{mmHg}$ and diastolic blood pressure was $=90 \mathrm{mmHg}$. The patients whose blood pressure levels normalized in the first 5 days subsequent to hospital admission were called hypertensive/normotensive, and those who remained hypertensive beyond that period were called hypertensive/ hypertensive.

Of the 100 patients hospitalized in the period studied, 17 did not take part in the study for different reasons (symptoms or signs of the syndrome of dependence on the occasion of clinical examination, early hospital discharge, patient's transferences, and evasions) and the following were excluded from the study: patients with positive serology for syphilis $(n=4)$, for Chagas' disease $(n=8)$, and for hepatitis $B$ and $C(n=6)$, patients with a positive pregnancy test $(n=4)$, patients who had received hypertonic glucose, those who had received fluid and electrolyte replenishment and other medications during hospitalization $(\mathrm{n}=12)$, and patients with incomplete laboratory tests $(n=5)$.

The sample of this comparative cross-sectional study comprised 44 patients divided into 2 groups based on the presence or absence of electrocardiographic changes.

Data are presented as mean \pm standard deviation. The statistical comparisons were performed with the chi-square test with the Yates correction or the 2-tailed Fisher test for qualitative variables and the Student $t$ test for quantitative variables. The $95 \%$ confidence intervals (CI) are shown for some data. The significance level of 5\% was adopted for statistical analysis. Data were processed and analyzed using Epi-Info 6.0 statistical software.

\section{Results}

The demographic characteristics, alcoholism and smoking pattern, and the characteristics of systemic arterial hypertension are shown in table I. One type of electrocardiographic change was identified in $33(75 \%)$ patients, 17 (38.6\%) of whom had more than 1 change. The most frequent changes present in $50 \%$ of the hypertensive/hypertensive patients and in only $8.3 \%$ of the hypertensive/normotensive patients were prolonged QTc interval (54.5\%), 


\begin{tabular}{|c|c|c|}
\hline & & $\%$ \\
\hline Mean age (years) & $41.4 \pm 3.4$ & \\
\hline \multicolumn{3}{|l|}{ Color } \\
\hline White & 30 & 68.2 \\
\hline Black & 9 & 20.5 \\
\hline Mulatto & 5 & 11.3 \\
\hline $\begin{array}{l}\text { Mean pure alcohol } \\
\text { consumption (grams/day) }\end{array}$ & $334 \pm 81$ & \\
\hline $\begin{array}{l}\text { Mean duration of } \\
\text { consumption (years) }\end{array}$ & $18 \pm 3.9$ & \\
\hline \multicolumn{3}{|l|}{ Smoking } \\
\hline No & 12 & 27.3 \\
\hline Yes & 32 & 72.7 \\
\hline \multicolumn{3}{|l|}{ Systemic arterial blood pressure } \\
\hline Normotensive patients & 22 & 50 \\
\hline Systolic blood pressure & $11.3 \pm 0.6$ & \\
\hline Diastolic blood pressure & $7.4 \pm 0.2$ & \\
\hline Hypertensive/normotensive patients & 12 & 27.3 \\
\hline Systolic blood pressure & $15.2 \pm 0.5$ & \\
\hline Diastolic blood pressure & $9.6 \pm 0.3$ & \\
\hline Hypertensive/hypertensive patients & 10 & 22.7 \\
\hline Systolic blood pressure & $16.4 \pm 0.6$ & \\
\hline Diastolic blood pressure & $10.6 \pm 0.5$ & \\
\hline \multicolumn{3}{|l|}{ Electrocardiogram } \\
\hline Without changes & 11 & 25 \\
\hline With changes & 33 & 75 \\
\hline
\end{tabular}

ventricular repolarization changes (25\%), and left ventricular hypertrophy (13.6\%). The prolonged QTc interval was associated with ventricular repolarization changes in 8 patients (18.2\%) and left ventricular hypertrophy in 5 (11.4\%) (tab. II). Arterial hypertension did not influence the prevalences of prolonged QTc intervals and ventricular repolarization changes.

The patients with and without electrocardiographic changes had hypocalcemia and mean serum levels of creatine phosphokinase, aspartate aminotransferase, and gamma glutamyl transferase above the normal limits.

Hypopotassemia was observed only in patients with

\begin{tabular}{|llr|}
\hline $\begin{array}{l}\text { Table II - Electrocardiographic changes in female alcoholics with no } \\
\text { clinical manifestations of cardiovascular disease }\end{array}$ \\
\hline Electrocardiographic changes & $\mathrm{n}^{\circ}$ & $\%$ \\
\hline I - Changes considered in isolation & & \\
Prolonged QT interval & 24 & 54.5 \\
(QTc > 440 milliseconds) & & \\
Changes in ventricular repolarization (CVR) & 11 & 25 \\
Left ventricular hypertrophy (LVH) & 6 & 13.6 \\
Sinus bradycardia (SB) & 4 & 9.1 \\
Sinus tachycardia (ST) & 3 & 6.8 \\
Left anterior superior & 2 & 4.5 \\
hemiblock (LASH) & & \\
Nodal inferior rhythm (NIR) & 1 & 2.3 \\
& & \\
II - Association of changes & & 18.2 \\
Prolonged QTc + CVR & 8 & 11.4 \\
Prolonged QTc + LVH & 5 & 4.5 \\
Prolonged QTc + ST & 2 & 2.3 \\
Prolonged QTc + SB & 1 & 2.3 \\
Prolonged QTc + LASH & 1 & \\
\hline
\end{tabular}

abnormal electrocardiograms, and elevation in alanine aminotransferase was found in those with normal electrocardiograms (tab. III).

The patients with abnormal electrocardiograms compared with those with normal electrocardiograms had a more elevated mean age $(\mathrm{P}=0.001 ; 95 \%$ CI of 2.89-10.91); a lower daily alcohol consumption $(\mathrm{P}=0.005 ; 95 \% \mathrm{CI}$ of 32.32 165.68); and more elevated serum levels of triglycerides $(\mathrm{P}=0.001 ; 95 \% \mathrm{CI}$ of $16.03-51.37)$, postprandial glycemia $(\mathrm{P}=0.001 ; 95 \% \mathrm{CI}$ of $15.45-53.54)$, and sodium $(\mathrm{P}=0.001$; $95 \%$ CI of $1.4-4.6)$. The opposite occurred with the following levels: fasting glycemia $(\mathrm{P}=0.001 ; 95 \% \mathrm{CI}$ of $4.95-$ 12.25), magnesium $(\mathrm{P}=0.034 ; 95 \%$ CI of $0.02-0.58)$, aspartate aminotransferase $(\mathrm{P}=0.018 ; 95 \% \mathrm{CI}$ of $1.75-17.25)$, alanine aminotransferase $(\mathrm{P}=0.001 ; 95 \% \mathrm{CI}$ of $8.08-25.92)$, and gamma glutamyl transferase $(\mathrm{P}=0.001 ; 95 \%$ CI of 21.39 61.01). No correlation was observed between the serum levels of gamma glutamyl transferase and daily alcohol consumption $(\mathrm{r}=0.15 ; \mathrm{F}=0.85,95 \% \mathrm{CI}$ of -0.29 to 0.33 ) (tab. III).

The relations between total cholesterol and HDL-cholesterol were $3.45(174.1 / 50.4)$ in the group with normal electrocardiographic findings and 3.37 (177.3/52.6) in the group with abnormal electrocardiographic findings.

Smoking was not a significant influence in the occurrence of electrocardiographic findings. The similarity between the levels of hemoglobin and albumin in patients with abnormal and normal electrocardiographic findings suggest that nutritional factors played no significant role in the occurrence of the electrocardiographic abnormalities (tab. III).

\section{Discussion}

Electrocardiographic abnormalities are common in alcoholism. Atrial fibrillation followed by atrial flutter and ventricular extrasystoles are the most frequently found abnormalities. In addition, atrioventricular conduction disorders, mainly first-degree atrioventricular block, bundlebranch block, left ventricular hypertrophy, and repolarization abnormalities are common electrocardiographic findings ${ }^{12,28,29}$.

In this study, the most frequent electrocardiographic changes were prolonged QT interval, ventricular repolarization changes, and signs of left ventricular hypertrophy, followed by rhythm abnormalities and conduction disorders of the cardiac stimulus. Unlike other studies, we found no arrhythmias. Even not considering the QT interval change, an abnormality not usually assessed on routine readings of electrocardiograms, the rate of electrocardiographic abnormalities was greater in the alcoholic patients $(61 \% \mathrm{x} 45 \%)$ than that observed in an epidemiological study conducted in an open population comprising individuals aged between 18 and 65 years, individuals with heart disease not excluded ${ }^{30}$.

The observation that the mean ages of the female patients with abnormal electrocardiographic findings, particularly those with a prolonged QT interval and changes in ventricular repolarization, were significantly greater than those of the patients with normal electrocardiographic fin- 


\begin{tabular}{|c|c|c|c|}
\hline Variable & $\begin{array}{l}\text { Without change } \\
\qquad \mathrm{n}=11\end{array}$ & $\begin{array}{l}\text { With change } \\
n=33\end{array}$ & $\mathrm{P}$ \\
\hline Age (years) & $36.2 \pm 11$ & $43.1 \pm 2.2$ & 0.001 \\
\hline Mean consumption of pure alcohol (g/day) & $409 \pm 119$ & $310 \pm 86$ & 0.005 \\
\hline Duration of consumption (years) & $18.2 \pm 7.8$ & $18.6 \pm 3.5$ & NS \\
\hline Smokers (tobacco) & $8(72.7)$ & $24(72.7)$ & NS \\
\hline Arterial hypertension & $4(66.4)$ & $12(36.4)$ & NS \\
\hline Hepatomegaly & $5(45.5)$ & $23(69.7)$ & NS \\
\hline Splenomegaly & $3(27.2)$ & $11(33.3)$ & NS \\
\hline Hemoglobin (11.9 to $16.3 \mathrm{~g} / \mathrm{dL})$ & $13.8 \pm 0.5$ & $13.6 \pm 1.2$ & NS \\
\hline Albumin $(3.5$ to $4.8 \mathrm{~g} / \mathrm{dL})$ & $3.9 \pm 0.5$ & $3.6 \pm 0.7$ & NS \\
\hline Fibrinogen (180 to $400 \mathrm{mg} / \mathrm{dL}$ ) & $287.5 \pm 44$ & $308.8 \pm 32.9$ & NS \\
\hline Prothrombin time (80 to $100 \%$ ) & $93.4 \pm 6.9$ & $90.7 \pm 6.8$ & NS \\
\hline Total cholesterol (200 to $239 \mathrm{mg} / \mathrm{dL}$ ) & $174.1 \pm 14.8$ & $177.3 \pm 29$ & NS \\
\hline LDL-cholesterol (130 to $159 \mathrm{mg} / \mathrm{dL})$ & $104.3 \pm 19.9$ & $101.2 \pm 20.8$ & NS \\
\hline HDL-cholesterol (desirable > $35 \mathrm{mg} / \mathrm{dL}$ ) & $50.4 \pm 8.2$ & $52.6 \pm 7.5$ & NS \\
\hline Triglycerides $(\leq 160 \mathrm{mg} / \mathrm{dL})$ & $96.8 \pm 25$ & $130.5 \pm 25.2$ & 0.001 \\
\hline Fasting glycemia (70 to $110 \mathrm{mg} / \mathrm{dL}$ ) & $79.6 \pm 7.7$ & $71 \pm 4.1$ & 0.001 \\
\hline Postprandial glycemia (70 to $110 \mathrm{mg} / \mathrm{dL}$ ) & $74.6 \pm 3.2$ & $109.1 \pm 31$ & 0.008 \\
\hline Creatine phosphokinase (10 to $70 \mathrm{U} / \mathrm{L}$ ) & $94.6 \pm 85$ & $78.0 \pm 38.4$ & NS \\
\hline Lactic dehydrogenase (100 to $200 \mathrm{U} / \mathrm{L}$ ) & $180.2 \pm 52.6$ & $166.5 \pm 13.9$ & NS \\
\hline Sodium $(138$ to $146 \mathrm{mEq} / \mathrm{L})$ & $138.3 \pm 4.3$ & $141.3 \pm 1$ & 0.001 \\
\hline Potassium (3.6 to $5.5 \mathrm{mEq} / \mathrm{L}$ ) & $3.6 \pm 0.3$ & $3.3 \pm \quad 0.3$ & 0.006 \\
\hline Calcium (8.8 to $11.0 \mathrm{mg} / \mathrm{dL}$ ) & $8.3 \pm 0.6$ & $8.1 \pm 0.5$ & NS \\
\hline Phosphorus ( 2.5 to $4.8 \mathrm{mg} / \mathrm{dL}$ ) & $3.1 \pm 0.6$ & $3.3 \pm 0.2$ & NS \\
\hline Magnesium (1.9 to $2.5 \mathrm{mEq} / \mathrm{L})$ & $2.5 \pm 0.6$ & $2.2 \pm \quad 0.3$ & 0.03 \\
\hline Aspartate aminotransferase ( 8 to $29 \mathrm{U} / \mathrm{L}$ ) & $39.7 \pm 18.2$ & $30.2 \pm 7.5$ & 0.02 \\
\hline Alanine aminotransferase (2 to $33 \mathrm{U} / \mathrm{L}$ ) & $38.7 \pm 24.1$ & $21.7 \pm 5.5$ & 0.001 \\
\hline Alkaline phosphatase (13 to $45 \mathrm{U} / \mathrm{L}$ ) & $30.1 \pm 17.4$ & $33.7 \pm 6.4$ & NS \\
\hline Gamma glutamyl transferase (4 to $18 \mathrm{U} / \mathrm{L}$ ) & $32.7 \pm 20.5$ & $73.9 \pm 30.2$ & 0.001 \\
\hline
\end{tabular}

dings, is in accordance with that observed in nonalcoholic persons. The prevalence of depolarization and repolarization changes increases with age, independently of alcohol consumption. As the mean age of the patients with electrocardiographic abnormalities was relatively low, it seems unlikely that age was the factor responsible for the changes.

The fact that the alcohol intake of patients with abnormal electrocardiographic findings is lower than that of patients with normal electrocardiographic findings during approximately equal periods suggests that individual differences exist in the vulnerability to the noxious effects of alcohol. This impression was reinforced by the different behaviors of several substances, such as triglycerides, glucose, hepatic enzymes, and some electrolytes in patients with normal and abnormal electrocardiograms. The serum levels of triglycerides in patients with electrocardiographic abnormalities were greater than those in patients with normal electrocardiograms. Prospective studies have established that hypertriglyceridemia is a risk factor for vascular disease, mainly coronary heart disease, in both sexes ${ }^{31}$. In our study, except for the changes related to ventricular repolarization, no other electrocardiographic abnormality suggestive of myocardial ischemia was found. It is worth noting that electrocardiography at rest is a procedure with low specificity for the diagnosis of ischemic heart disease. The protective effect provided by alcohol ingested in the form of alcoholic beverages ${ }^{32}$ could depend on several factors, such as an increase in HDL-cholesterol levels, inhibition of platelet ag- gregation, increased serum fibrinolytic activity, and a possible increase in insulin sensitivity. The major protective factor could be the increase in HDL-cholesterol levels ${ }^{33}$. High HDL-cholesterol levels ( 50 to $60 \mathrm{mg} / \mathrm{dL}$ ) are associated with a low risk for coronary artery disease, and a $1 \%$ reduction in this lipid fraction increases the risk for the disease by $3 \%{ }^{34}$. In our study, the patients with and without electrocardiographic changes had mean HDL-cholesterol levels above $50 \mathrm{mg} / \mathrm{dL}$. In addition, the mean levels of total cholesterol and LDL-cholesterol remained within the normal range and below the levels considered risky for artery disease. A higher risk for coronary artery disease is estimated to occur when the ratio between total cholesterol and HDL-cholesterol is greater than $5^{35}$. In our study, that ratio was similar for the groups with and without electrocardiographic abnormalities (3.37 and 3.45, respectively), far below the value of risk.

The differences observed in fasting and postprandial glycemias according to the presence or absence of electrocardiographic abnormalities are difficult to analyze. Glycemia control does not only depend on insulin and glucagon secretion, but also on adrenergic, cholinergic, and possibly peptidergic mechanisms ${ }^{36}$, during the phase of alcohol withdrawal, when plasma concentrations of aldosterone, norepinephrine, epinephrine, and cortisol increase ${ }^{37}$, and manifestations of increased sympathetic nervous system activity occur ${ }^{38}$.

The prevalence of hypocalcemia, a condition in which increased muscle irritability occurs, was similar in patients 
with and without electrocardiographic abnormalities. Hypopotassemia was observed exclusively in patients with electrocardiographic abnormalities, but it was only significant in patients with prolonged QT or ventricular repolarization changes. Only patients with prolonged QT had hypomagnesemia, but in alcoholics a depressed $\mathrm{T}$ wave and prolonged QT interval may be related to hypopotassemia and hypomagnesemia. Although low levels of potassium and magnesium have been associated with a greater prevalence of ventricular arrhythmias ${ }^{39}$, this was not observed in our study.

Aminotransferases and gamma glutamyl transferase have different behaviors according to the presence or absence of electrocardiographic changes. While the serum levels of both aminotransferases were significantly lower in patients with electrocardiographic changes, the level of gamma glutamyl transferase was more elevated. It is worth emphasizing that no correlation was observed between the serum levels of gamma glutamyl transferase and daily alcohol consumption.

The prevalences of hepatomegaly and splenomegaly were similar in women with and without electrocardiographic changes, assuming that the extension of the QT interval in alcoholics does not depend on the autonomic cardiac function, but is related to the severity of the hepatopathy 40 or to the simple presence of portal hypertension, regardless of the degree of hepatic dysfunction ${ }^{41}$. In our study, the absence of symptoms and signs of hepatic dysfunction and portal hypertension, the absence of abnormalities in the biochemical tests assessing liver function (albumin, fibrinogen, and prothrombin time), as well as the presence of nor- mal serum levels of alanine aminotransferase (the enzyme that most reliably indicates hepatic lesions) in patients with abnormal electrocardiograms suggest that the change in the QT interval depends on factors other than the existence of hepatopathy and portal hypertension.

Approximately $50 \%$ of the patients in our study had arterial hypertension on hospital admission, but only $22.7 \%$ remained hypertensive in the subsequent days. An electrocardiographic change suggestive of ventricular hypertrophy was present in $50 \%$ of the hypertensive/hypertensive patients and in only $8.3 \%$ of the hypertensive/normotensive patients.

Creatine phosphokinase, the enzyme that is altered in lesions of several tissues, especially the skeletal and smooth muscles, was elevated in patients with and without electrocardiographic changes. In alcoholics, these enzyme changes have been attributed to changes in skeletal muscles ${ }^{42,43}$.

The association between smoking and alcoholism is very frequent ${ }^{44,45}$. Alcohol and tobacco may interact in the production of hepatic changes ${ }^{46}$. However, in this study, no influence of smoking in the prevalence of electrocardiographic changes was observed.

The results of our study suggest that electrocardiography, a noninvasive method available in almost all medical facilities, should be part of the preliminary assessment of alcoholics.

\section{Acknowledgments}

We thank CNPq and FAPEMIG for their support.

\section{References}

1. Oparil S. Arterial Hypertension. In: Wyngaarden JB, Smith Jr. LH, Bennett JC, eds. Cecil Textbook of Medicine. 19th ed. Philadelphia, Saunders; 1992; 258-74.

2. Puddey IB, Beilin LJ, Vandongen R, Rouse IL, Rogers P. Evidence for a direct effect of alcohol consumption on blood pressure in normotensive men: a randomized controlled trial. Hypertension 1985; 7: 707-13.

3. Klatsky AL, Friedman GD, Siegelaub AB, Gérard MJ. Alcohol consumption and blood pressure: Kaiser - permanents multiphasic health examination data. $\mathrm{N}$ Engl J Med 1977; 296:1194-200.

4. Wynne J, Braunwald E. As miocardiopatias e as miocardites. In: Braunwald E, Isselbacher KI, Petersdorf RG, Wilson JD, Martin JB, Fauci AS eds. Harrison- Medicina Interna, $11^{\text {a }}$ ed, vol 1. Rio de Janeiro: Guanabara Koogan, 1988; 927-33.

5. Urbano-Márquez A, Estruch R, Fernández-Solá J et al. The greater risk of alcoholic cardiomyopathy and myopathy in women compared with men. JAMA 1995; 274: $149-54$

6. Kasper EW, Agema WRP, Hutchins GM et al. The cause of dilated cardiomyopathy: a clinicopathologic review of 673 consecutive patients. J Am Coll Cardio 1994; 23: 586-90

7. Teragaki M, Takeuchi K, Takeda T. Clinical and histological features of alcohol drinkers with congestive heart failure. Am Heart J 1993; 125: 808-17.

8. Piano MR, Schwertz DW. Alcoholic heart disease: a review. Heart-Lung 1994; 23: 3-17.

9. Burch GE, Gilles TD. Alcoholic cardiomyopathy: concept of disease and its treatment. Am J Med 1971; 101: 461-4.

10. Gillet $\mathrm{C}$, Julliere $\mathrm{Y}$, Pirollet $\mathrm{P}$ et al. Alcohol consumption and biological markers for alcoholism in idiopathic dilated cardiomyopathy: a case-controlled study. Alcohol Alcohol 1992; 27: 353-8.
11. Fischbein L, Sachs RN, Geay Det al. Study of HLA system A and B antigens in dilated cardiomyopathy associated with alcoholism. Arch Mal Coeur 1987; 80: 1171-5.

12. Moreira DAR, Reyes CAS. Bases eletrofisiológicas da fibrilação atrial - fatores desencadeantes e de perpetuação. Rev Soc Cardiol Estado de São Paulo 1994; 3: 207-13.

13. Facour SM. Intramyocardial small vessels disease in chronic alcoholism. Am Heart J 1976; 92: 561-75.

14. Pintar K, Woalnsky BM, Cubbay ER. Alcoholic cardiomyopathy. Can Med Assoc J 1969; 93: 103-7.

15. Neville JN, Eagles JA, Sampson G, Samson G, Olson RE. Nutricional status of alcoholics. Am J Clin Nut 1968; 21 : 1.329-40.

16. Pinn G, Bovet P. Alcohol-related cardiomyopathy in Seychelles. Med J Aust 1991; 155: 529-32.

17. Walsh TK, Vacek JL. Ethanol and heart disease: an underestimated contributing factor. Postgrad Med 1986; 79: 60-3.

18. Regan TJ. Alcoholic cardiomiopaty. Prog Cardiovasc Dis 1984; 27: 141-52.

19. Hochgraf PB, Zilberman ML, Andrade AG. Women alcoholics - social, demographic and clinical characteristics in a Brasilian sample. Alcohol Alcohol 1995; 30: 427-32.

20. Pechansky F, Soibelman M, Gus G. Consumo de álcool em mulheres: preconceito? Revista ABP-APAL 10: 87-90.

21. Marshall AW, Kingstone D, Boss M, Morgan MY. Ethanol elimination in males and females: relationship to menstrual cycle and body composition. Hepatology 1983; 3: 701-6.

22. Frezza M, DiPadova C, Pozzato G et al. High blood alcohol levels in women: the role of decreased gastric alcohol dehydrogenase activity and first-pass metabolism. N Engl J Med 1990; 322: 95-9. 
23. Classificação de Transtornos de Doenças Mentais e de Comportamento da CID 10 (1997): Descrições Clínicas e Diretrizes Diagnósticas. Organização Mundial de Saúde - Genebra, Artes Médicas, Porto Alegre.

24. Borini P. Anamnese psiquiátrica clínica, exame físico exames complementares estruturados e informatizados para aplicação em alcoolistas. J Bras Psiq 1990; 39: 250-65.

25. Fisch C. Eletrocardiografia e vetocardiografia. In: Braunwald W ed. Tratado de Medicina Cardiovascular, vol 1, $3^{\text {a }}$ ed. São Paulo, Roca, 1991; 189-233.

26. Tranchesi J. Eletrocardiograma Normal e Patológico - Noções de vectocardiografia. São Paulo: Atheneu, 1975; 63-92

27. Joint National Commitee on Detection, Evaluation, and Treatment of High Blood Pressure. The sixth report of the Joint National Commitee on Detection, Evaluation, and Treatment of High Blood Pressure (JNC VI). Arch Intern Med 1997; 157: 2413-46.

28. Regan TJ. Alcoholic cardiomyopathy. In: Zipes DP, Rowlands DJ eds. Progress in Cardiology. Philadelphia, Lea and Fibiger, 1989; 129.

29. McCall D. Alcohol and the cardiovascular system. Curr Probl Cardiol 1987; 12 . $1-414$.

30. Johnson JL, Heineman EF, Heiss G, Hames CG, Tyroler HA. Cardiovascular disease risk factors and mortality among black women and white women aged 4064 years in Evans County, Georgia. Am J Epidemiol 1986; 123:209-20.

31. Hokanson JE, Austin MA. Triglyceride is a risk factor of coronary disease in men and women. A meta-analysis of population based prospective studies. Circulation 1993; 88: 510-4.

32. Klatsky AL, Armstrong Ma, Friedman GD. Red wine, white wine, liquor, beer, and risk for coronary artery disease hospitalization. Am J Cardiol 1997; 80: 416-20.

33. RimmEB, Williams P, Fosher K, Criqui M, Stampfer MJ. Moderate alcohol intake and lower risk of coronary heart disease: meta-analysis of effects on lipids and haemostatic factors. BMJ 1999; 319: 1523-8.

34. Consenso Brasileiro sobre Dislipidemia - Detecção, Avaliação e Tratamento. Sociedade Brasileira de Cardiologia. Arq Bras Cardiol 1996; 67: 113-28.
35. Assmann G, Schulte H. The importance of triglycerides - results from The Prospective Cardiovascular Munster (PROCAM) Study. Eur J Epidemiol 1992; 8: 99-103.

36. Patto RJ, Neves MM, Russo EK, Borges DR. A hipoinsulinemia do alcoólatra independe do eixo enteroinsular.Rev Paul Med 1985,103: 15-18, 1985.

37. De Marchi S, Cecchin E, Basile A et al. Renal tubular dysfunction in chronic alcohol abuse - effects of abstinence. N Engl J Med 1993, 329: 1927-34.

38. Beevers DG, Bannan LT, Saunders JB, Paton A, Walters JR. Alcohol and hypetension. Contrib Nephrol 1982, 30: 92-7.

39. Tsuji H, Vendititti FJ Jr, Evans JC, Larson MG, Levy D. The associations of levels of serum potassium and magnesium with ventricular premature complexes (the Framingham Heart Study). Am J Cardiol 1994; 74: 232-5.

40. Puthumana L, Edwin D, Chaudhary V, Thuluvath PJ. Prolonged QTc interval seen in patients with cirrhosis is related to the severity of liver disease and not with autonomic cardiovascular reflex. Gastroenterology 1999; $116(4$ - part 2): L0371, A 1264

41. Valeriano V, Trevisani F, Merli M et al. Prolongation of the QT interval in cirrhosis: role of portal hypertension. Gastroenterology 1999; 116 (4 - part 2): L0377, A 1266.

42. Borini P, Guimarães RC. Indicators of inflammation and cellular damage in chronic asymptomatic or oligosymptomatic alcoholics: correlation with alteration of bilirubin and hepatic and pancreatic enzymes. Rev Hosp Clín Fac Med S Paulo 1999; 54: 53-60.

43. Urbano-Marquez A, Estruch R, Navarro-Lopez F et al. The effects of alcoholism on skeletal and cardiac muscle. N Engl J Med 1989; 320: 409-15.

44. Bobo JK, Gilchrist L. Urging the alcoholic client to quit smoking cigarettes Addict Behav 1983; 8: 297-305.

45. Borini P, Silva CO. Aspectos demográficos, epidemiológicos e sociais do alcoolismo: uma análise de alcoolistas internados em hospital psiquiátrico. Rev ABP-APAL 1989; 11: 89- 96.

46. Borini P. Interação álcool-fumo na agressão hepática. Rev Hosp Clín Fac Méd S Paulo 1995; 50: 259-63. 